\title{
O Direio de Aprender dos Estudantes e o Direito dos Professores de Ensinar com Dignidade
}

\author{
Marilaine de Castro Pereira Marques ${ }^{I}$ Edileuza Valeriana de Farias Venturin ${ }^{2}$ \\ Simone José Aparecida da Silva Santos ${ }^{3}$ Marlize Reffatti Zinelli ${ }^{4}$
}

\begin{abstract}
Resumo: O presente artigo tem por escopo discorrer sobre o direito de aprender de crianças e adolescentes, bem como o direito dos professores de terem as condições necessárias para realizar seus trabalhos com dignidade. Para tanto utilizou-se o método de procedimento bibliográfico. O trabalho foi desenvolvido no período de setembro de 2015 a setembro de 2016. Os avanços da ciência e da tecnologia têm possibilitado entender que cada indivíduo tem um perfil de aprendizagem. Assim, os professores precisam estar atentos para possibilitar as condições adequadas para que os alunos aprendam, visto que na contemporaneidade, a educação é direito de todos. O direito de aprender da criança e do adolescente está garantido pela legislação brasileira de forma exemplar. Os professores estão sendo cobrados por todos os lados, porém as condições para desenvolver seus trabalhos não estão compatíveis com o grau das exigências e com as responsabilidades que têm. É preciso que a gestão esteja atenta aos desafios dos professores e busque solucionar ou amenizar os mesmos, para que estes tenham condições materiais e psicológicas para realizarem seus trabalhos. Os pais devem acompanhar a vida escolar dos filhos auxiliando-os em suas dificuldades e sendo parceiros da escola. É preciso defender o direito do aluno de aprender e igualmente o direito do professor de ser respeitados no seu espaço de ensinar. Os governantes e a sociedade precisam reconhecer não somente nas páginas dos diversos documentos que oferecem as bases legais da educação e dos direitos humanos, mas sobretudo, com iniciativas concretas para os sujeitos professor/aluno, do contrário, as referidas legislações continuarão a se evidenciarem entre as mais belas do planeta, sem gerar as transformações que trazem em seus bojos.
\end{abstract}

Palavras-chave: Educação. Direito do aluno. Direito do professor.

\section{The Student Learning Day and The Right of Teachers to Teach Dignity}

\begin{abstract}
The purpose of this article is to discuss the right to learn of children and adolescents, as well as the right of teachers to have the necessary conditions to carry out their work with dignity. For this, the method of bibliographic procedure was used. The work was developed from September 2015 to September 2016. Advances in science and technology have made it possible to understand that each individual has a learning profile. Thus, teachers need to be attentive to enable adequate conditions for students to learn, since at the present time, education is the right of all. The right of children and adolescents to learn is guaranteed by Brazilian legislation in an exemplary way. Teachers are being charged on all sides, but the conditions for developing their work are not compatible with the degree of the demands and the responsibilities they have. It is necessary that the management is attentive to the challenges of the teachers and seeks to solve or to soften them, so that they have the material and psychological conditions to carry out their work. Parents should follow the school life of their children by helping them in their difficulties and being school partners. It is necessary to defend the right of the student to learn and equally the right of the teacher to be respected in his space of teaching. Governors and society need to recognize not only the pages of the various documents that provide the legal basis for education and human rights, but above all, concrete initiatives for the subjects Otherwise, these legislations will continue to be among the most beautiful on the planet, without generating the transformations they bring in their minds.
\end{abstract}

Palavras-chave: Education. Right of the student. Right of the teacher.

\footnotetext{
${ }^{1}$ Licenciada em Ciências Biológicas pela Universidade do Estado de Mato Grosso (UNEMAT) de Alta Floresta; Mestre em Educação pela Universidade Federal de Mato Grosso; Professora das Escolas Estaduais Dom Bosco e 19 de Maio; Professora da Faculdade de Alta Floresta (FAF) e da Faculdade de Direito de Alta Floresta. marilainecastro@hotmail.com

${ }^{2}$ Mestra em Direitos Difusos e Coletivos; Especialista em Processo Civil, Graduada em Direito, Graduanda em Ciências Sociais; Professora do Curso de Direito da Faculdade de Alta Floresta (FADAF) e do Curso de Direito da Universidade Estadual de Mato Grosso (UNEMAT); Advogada.edileuzafarias@hotmail.com

${ }^{3}$ Licenciada em Matemática pela Universidade do Estado de Mato Grosso (UNEMAT) de Alta Floresta; Mestre em Educação Matemática pela Universidade Federal de Mato Grosso (UFMT); Professora da Escola Estadual Jaime Veríssimo de Campos.

${ }^{4}$ Mestre em Ciências Ambientais e Desenvolvimento Sustentável pela Universidade Técnica de Comercialización y Desarrollo - UTCD (Universidad de Asunción-Paraguay), Professora da Escola Técnica Estadual (ETE) e da Faculdade de Direito de Alta Floresta - FADAF. Endereço eletrônico: lize.zinelli@ outlook.com.br
} 


\section{Introdução}

O direito de aprender da criança e do adolescente está garantido pela legislação brasileira de forma exemplar. No momento histórico intitulado de era do conhecimento, no Brasil não se questiona a excelência das legislações voltadas para esse fim. O que se indaga é até que ponto existe uma relação coerente, entre o direito previsto na legislação e o direito de fato dos sujeitos em voga? O presente artigo tem por escopo discorrer sobre essa questão e para tanto utilizou-se o método de procedimento bibliográfico. O mesmo foi desenvolvido no período de setembro de 2015 a setembro de 2016 e os dados foram coletados em fontes variadas, impressas e digitalizadas.

Estruturou-se o trabalho em três partes: introdução; resultados e discussão e considerações. A primeira parte diz respeito ao tema da pesquisa, problematização, objetivo, metodologia e forma de organização do artigo. A segunda parte trata-se das seguintes questões: o direito de aprender de acordo com a legislação que concede a referida prerrogativa; os princípios da formação humanista que orientam a educação na contemporaneidade; os índices das avaliações externas, realizadas pelos órgãos avaliadores e o papel dos professores e pais dos estudantes. Por fim, na última parte serão apresentadas as considerações finais.

\section{Resultados e Discussão}

O direito de aprender das crianças e adolescentes sob o prisma da legislação é algo que ganhou desenvoltura nas últimas décadas. Também do campo do discurso dos educadores, governantes e estudiosos da questão constata-se que há uma grande defesa dessa prerrogativa. Na prática, porém, a aprendizagem dos educandos da educação básica, mostra-se insipiente.

Não se pode falar do direito de aprender dos estudantes sem levar em conta o direito do outro sujeito do processo educativo, o professor. Este precisa de dignidade para ensinar e cumprir com êxito sua função. A seguir serão apresentadas informações que indicam o 
paradoxo que envolve a legislação e a prática do direito de aprender dos estudantes e o direito do professor de ensinar com dignidade.

\section{Bases legais do direito de aprender de crianças e adolescentes}

O cidadão é um ser que exerce de forma crítica e fundamentada sua cidadania, ou seja, usufruindo de seus direitos e cumprindo seus deveres com responsabilidade ética e moral. Ao falar em cidadania é fundamental buscar amparo na Constituição da Republica Federativa do Brasil (Brasil, 1988), que instituiu o Estado Democrático, responsável por assegurar os direitos sociais e individuais das pessoas de sua jurisdição.

De acordo com o Art. 205 da Constituição Federal Brasileira (1988) “a educação, direito de todos e dever do estado e da família, será promovida e incentivada com a colaboração da sociedade, visando o pleno desenvolvimento da pessoa, seu preparo para a cidadania e sua qualificação para o mundo do trabalho".

O pleno desenvolvimento da pessoa se faz com uma proposta pedagógica cujos princípios estejam voltados para garantir os direitos que todo cidadão tem de aprender. Por sua vez, a qualificação para o mundo do trabalho também implica que os docentes trabalhem sem dicotomizar as atividades intelectuais das práticas e do contexto geral onde os indivíduos estão inseridos. Nesse processo formativo é necessário que os conteúdos conceituais, atitudinais e procedimentais sejam trabalhados articuladamente, para que o educando se forme com o compromisso de utilizar seus conhecimentos com competência e ética profissional.

Muitos profissionais que tiveram formação primorosa do ponto de vista técnico e científico têm colocado seus conhecimentos a serviço de interesses individuais de maneira desonesta. O Brasil está cheio desses exemplos veiculados pela mídia; pessoas com grande capacidade intelectual que deveriam zelar pelo bem estar do país e que estão lesando a população. Exemplos de honestidade e respeito ao próximo também têm emergido nesse cenário, onde coexistem as forças de transformação e de conservação social. Esses indicadores demonstram o quanto é importante uma formação integral, que considera os aspectos cognitivos afetivos e sociais dos humanos. 
As escolas para cumprir suas incumbências precisam organizar suas propostas de trabalho de acordo com a Lei $n^{\circ}$ 9394/96, que estabelece as diretrizes e bases da educação nacional (LDBEN). Em seu Art. 12 a LDBEN expõe que as unidades escolares do seu sistema de ensino, terão as seguintes responsabilidades:

I - elaborar e executar sua proposta pedagógica; II - administrar seu pessoal e seus recursos materiais e financeiros; III - assegurar o cumprimento dos dias letivos e horas-aula estabelecidas; IV - velar pelo cumprimento do plano de trabalho de cada docente; V - prover meios para a recuperação dos alunos de menor rendimento; VI articular-se com as famílias e a comunidade, criando processos de integração da sociedade com a escola;

Todos os itens apresentados anteriormente são igualmente importantes para a promoção de uma educação de boa qualidade, visto que diz respeito ao planejamento, a administração, ao cumprimento do plano de trabalho, a recuperação e a integração escola/família. Contudo, com a finalidade de ressaltar que todo aluno tem direito de aprender, recorre-se ao parágrafo $\mathrm{V}$ da $\mathrm{LDB}$, que explicita a obrigatoriedade das escolas organizarem formas de recuperação para os alunos que por algum motivo não conseguiram aprender determinado conteúdo. Esse parágrafo não deixa dúvida de que o aluno vai à escola para aprender e que a função da escola é ensinar.

Quando se menciona a palavra escola, refere-se ao coletivo de pessoas que nela atuam e não às paredes e coisas que constituem o local, onde se desenvolve a atividade educativa. Sabe-se que os desafios que os docentes enfrentam em sala de aula são imensos e que os mesmos precisam ser amparados com formação continuada adequada e orientação pedagógica. Essa proposição encontra respaldo no Plano Nacional de Educação, decênio 2014-2024.

O Plano Nacional de Educação (PNE) constitui um instrumento de planejamento do Estado democrático de direito que tem por escopo orientar a efetivação e o aprimoramento de políticas públicas do setor. Foi elaborado de forma participativa envolvendo diversos atores sociais e o poder público. O plano definiu objetivos, metas e diretrizes para todos os níveis de ensino. Foi aprovado pela Lei $\mathrm{n}^{\mathrm{o}} 13.005$ de 25 de junho de 2014, com vigência para 10 anos. O Art. $2^{\circ}$ do referido Plano apresenta dez diretrizes, a saber: 
I - erradicação do analfabetismo; II - universalização do atendimento escolar; III superação das desigualdades educacionais, com ênfase na promoção da cidadania e na erradicação de todas as formas de discriminação; IV - melhoria da qualidade da educação; $\mathrm{V}$ - formação para o trabalho e para a cidadania, com ênfase nos valores morais e éticos em que se fundamenta a sociedade; VI - promoção do princípio da gestão democrática da educação pública; VII - promoção humanística, científica, cultural e tecnológica do país; VIII - estabelecimento de meta de aplicação de recursos públicos em educação como proporção do Produto Interno Bruto (PIB), que assegure atendimento às necessidades de expansão, com padrão de qualidade e equidade; IX - valorização dos(as) profissionais da educação; X - promoção dos princípios do respeito aos direitos humanos, à diversidade e à sustentabilidade socioambiental.

Os parágrafos IV e V do Plano Nacional, decênio 2014-2024 corroboram as proposições do Artigo 205 da Constituição Feral do Brasil, no que se refere à formação para a cidadania, a qualificação para o mundo do trabalho e a melhoria da qualidade da educação. Os parágrafos em evidência também estão alinhados com a nova LDB, no 9394/96, pois de acordo com os parágrafos VII e IX do Art. $3^{\circ}$ da Lei em voga, o ensino deve ter por princípio, entre outros, a valorização do profissional da educação escolar e a garantia de padrão de qualidade.

A garantia do padrão de qualidade também é respaldada pelo Estatuto da Criança e do Adolescente, aprovado pela Lei $\mathrm{n}^{\circ} 8.069$ de 13 de julho de 1990. O Art. $3^{\text {o }}$ do Estatuto esclarece que:

\begin{abstract}
A criança e o adolescente gozam de todos os direitos fundamentais inerentes à pessoa humana, sem prejuízo da proteção integral de que trata esta Lei, assegurandose-lhes, por lei ou por outros meios, todas as oportunidades e facilidades, a fim de lhes facultar o desenvolvimento físico, mental, moral, espiritual e social, em condições de liberdade e de dignidade.
\end{abstract}

Considerando o disposto no Art. $3^{\circ}$ do Estatuto, mais uma vez, o direito de aprender de crianças e adolescentes está resguardado; logo, se existe o direito desses sujeitos de aprender, existe também o dever da escola de oferecer uma educação de boa qualidade a todos.

A contemporaneidade é uma época de grandes crises nos diversos setores da sociedade: na saúde, na educação, na família, na política e na economia. Essas crises são oriundas de uma crise maior, que é a crise da civilização atual, na qual a maioria das pessoas querem seus direitos, esquecendo as vezes que o cidadão de direito também ter dever. 
É preciso resgatar valores humanos indispensáveis para a construção de sociedade mais justas e solidárias. Sem esse resgate fica mais difícil transformar as leis em concreticidade histórica. A educação é fator preponderante para o desenvolvimento das nações, visto que por meio dela o ser humano amplia suas possibilidades de melhorar sua qualidade de vida e contribuir com maior êxito para o progresso de seu país.

Daí a importância da promoção de uma educação de boa qualidade, que ofereça ao educando não somente o direito de estar na escola, mas, de nela aprender significativamente. Uma educação de boa qualidade precisa propiciar ao educando condições para que o mesmo desenvolva as capacidades básicas estipuladas para cada nível de ensino para que o referido sujeito tenha condições de falar, escrever e opinar sobre os conteúdos estudados, com rigor científico e competência política.

\section{A educação e os princípios da formação humana}

A educação na perspectiva da formação humana prima pelo desenvolvimento integral da pessoa e aponta para a necessidade de propiciar condições para que todos os educandos desenvolvam paulatinamente suas capacidades afetivas, cognitivas, sociais e espirituais. As tendências pedagógicas atuais pautadas nesses princípios explicitam que "pensar uma sociedade altruísta, solidária e humanizada, onde a inclusão social, política e econômica é condição essencial para a existência humana, é também tarefa da Educação" (MATO GROSSO, 2012).

Os responsáveis pelo sistema de ensino em cada estado brasileiro buscam implementar propostas que coadunam com as determinações das leis e diretrizes que norteiam a educação nacional. A Secretaria de Estado de Educação (SEDUC/MT) em 1999 sugeriu a proposta escola organizada por ciclos de formação humana para o Ensino Fundamental e em 2000 enviou às escolas um documento orientador para sua implantação (MATO GROSSO, 2000). O objetivo maior da iniciativa foi "garantir aos educandos o direito constitucional à continuidade e terminalidade dos estudos escolares" (MATO GROSSO, 2000, p. 17).

A organização do ensino em Ciclos de Formação Humana, 
possibilita um atendimento mais adequado e atencioso aos educandos, considerando não apenas os aspectos cognitivos - tradicionalmente considerados na organização do currículo escolar - mas também os aspectos sociais, morais, éticos e afetivos constitutivos da natureza humana, num tempo escolar demarcado por critérios diferentes dos estabelecidos numa escola seriada,- embasada teóricometodologicamente no paradigma positivista e funcionalista, que pela sua natureza, ignora a flexibilidade, a mobilidade e a possibilidade diferenciada de avanços na apropriação do conhecimento e na constituição da cidadania. Nos Ciclos de Formação respeita-se a organização das turmas por idade, como decorrência da concepção de que o aluno, na convivência com seus pares da mesma idade, tem maior oportunidade de vivenciar um processo de interação riquíssimo que facilita, mediante as trocas socializantes, a construção de sua identidade e auto-imagem própria de sua faixa etária (MATO GROSSO, 2000, p. 26).

A proposta foi organizada para possibilitar a aprendizagem significativa, de forma democrática, para atender toda diversidade que emerge no contexto escolar. A avaliação diagnóstica e formativa é fator preponderante nesse cenário, visto que indica o que os educandos aprenderam e o que ainda precisam de ajuda para aprender. Trata-se de uma política que em tese tem tudo para ser uma iniciativa de excelência, contudo no que diz respeito à prática constata-se por meio da mídia e também pelo discurso dos próprios profissionais da educação, que vários fatos desvirtuaram o escopo inicial da proposta.

Um desses fatos é a resistência que vários educadores manifestam pela política em voga. Alguns afirmam que a referida política é a desencadeadora da péssima qualidade da educação, visto que a não reprovação induz o educando a ser relapso; outro acontecimento diz respeito à forma que a avaliação é utilizada em algumas escolas, com a finalidade de mensurar o educado e não para gerar intervenções favoráveis ao bom desenvolvimento do processo educativo. Certamente há outros episódios tão desafiadores quantos esses, tais como as condições de trabalho dos professores, seus planos de carreira e os baixos salários, contudo, quem assume a docência, o faz com toda contradição que envolve esse setor de atividade humana e estas não podem servir para justificar o cenário onde a qualidade da educação está aquém do que apregoam os documentos oficiais que explicitam a qualidade social da mesma.

A história da educação está repleta de exemplos de que mesmo quando a reprovação era incisiva nas propostas escolas, a evasão, a repetência e a qualidade do ensino eram problemas graves a serem enfrentados pelas escolas; no entanto, como a educação não era para todos, aqueles alunos que não se enquadravam na sistemática da escola eram excluídos e responsabilizados pelos seus próprios fracassos. 
Em 1986, no período de 02 a 05 de setembro, ocorreu a IV Conferência Brasileira de Educação em Goiânia. As entidades organizadoras do evento foram: Associação Nacional de Educação (ANDE); a Associação Nacional de Pesquisa e Pós-graduação em Educação (ANPEd) e o Centro de Estudo Educação e Sociedade (CEDES). Participaram da Conferência cinco mil pessoas de todos os estados do país e o debate sobre as problemáticas da educação brasileira gerou a estruturação de uma carta institucional que foi intitulada de Carta de Goiânia. Nessa carta destacaram os problemas crônicos da educação, entre eles, o fato de que $50 \%$ dos alunos da época eram reprovados ou excluídos na primeira série do Ensino Fundamental e a necessidade de melhorar a qualidade do ensino (GIRALDELLI Jr., 2000).

Na década de 80, as escolas públicas brasileiras - em geral - eram seriadas, o sistema de ensino não era includente, ou seja, a educação era para os que conseguiam se enquadrar na sistemática da escola. Mesmo assim, não havia uma qualidade satisfatória na educação no Brasil. Ao fazer um comparativo das políticas educacionais da década de $80 \mathrm{com}$ as políticas atuais, bem como dos problemas educativos ao longo das ultimas décadas, compreende-se que o fracasso escolar e a precária qualidade de ensino não são problemas emergentes da escola organizada por ciclos de formação humana. Entende-se que os mesmos constituem problemáticas que remontam muitas décadas e que requerem enfrentamento primoroso dos profissionais da educação, dos governantes, das instituições formadoras de docentes e da sociedade.

O Instituto Nacional de Estudos e Pesquisa Educacionais Anísio Teixeira indica que a maioria das crianças e adolescentes estão nas escolas, mas, não estão desenvolvendo as potencialidades necessárias. Também é verdade que muitos avanços foram conquistados com o advento da LDB n. 9394/96 nos últimos anos, como por exemplo, a democratização das vagas nas escolas, a valorização dos profissionais da educação básica e a proposição de que os educandos devem ser formados para a cidadania e para o mundo do trabalho.

A política da escola organizada por ciclos de formação humana veio para contrapor a escola seriada, no sentido que tem como foco a democratização da educação e a melhoria da qualidade do ensino. $\mathrm{O}$ arcabouço filosófico, epistemológico, antropológico, metodológico e psicopedagógico da proposta esclarece que todos os educandos têm direito de aprender e podem aprender se forem criadas as situações pedagógicas necessárias para os diversos perfiz 
de aprendizagem. Também destaca a responsabilidade dos educadores, da família e do poder público na promoção da educação humanista.

Atualmente os avanços da ciência e da tecnologia têm possibilitados vários estudos, os quais indicam que cada ser tem um perfil de aprendizagem. Assim, os professores precisam estar atentos para essa questão visando possibilitar as condições adequadas para que todos aprendam, visto que na contemporaneidade, a educação é direito de todos, conforme apregoam a Constituição da República Federativa do Brasil de 1988; a LDB n. 9394/96; o Plano Nacional de Educação, decênio 2014-2024; e as Orientações Curriculares de Mato Grosso - MT (MATO GROSSO, 2012).

\section{Formação e condições de trabalho dos professores}

A formação dos professores, suas jornadas de trabalho e as demais condições em que desenvolvem suas tarefas, são questões que precisam ser levadas em conta quando se discute a qualidade da educação e o direito de aprender dos educandos. Educandos e educadores são sujeitos do processo ensino-aprendizagem e considerando a complexidade dessa relação, fica difícil separar de forma abrupta a qualidade de aprender dos estudantes e a qualidade para ensinar dos professores.

No que diz respeito à formação inicial, geralmente oferecida nas instituições de ensino superior, esta constitui uma importante base para o exercício docente. Por sua vez, a formação continuada representa para o profissional a possibilidade de manter-se atualizado para exercer a profissão. Em seu cotidiano laboral a maioria depara com jornadas exaustivas de trabalho desenvolvidas muitas vezes em duas ou mais escolas.

A legislação vigente aponta para a necessidade de investimentos na valorização dos docentes - LDB, N. 9394/96, Plano Nacional da Educação, decênio 2014-20124, entre outras para que os referidos profissionais tenham melhores carreiras e condições de labor, o que em última instância concorre positivamente para a melhoria da qualidade social da educação. Sabe-se que em todas as categorias há profissionais de excelência e profissionais de competência duvidosa. Nesse sentido, os órgãos que têm competência de gerenciar os sistemas de ensino público precisam avançar no quesito avaliação profissional, bem como, na 
efetivação coerente, do que se encontra nas Leis que regem a educação, para diminuir o foço existente entre esses documentos oficiais e o cotidiano de educandos e educadores nas escolas.

Vale destacar que as legislações delimitam responsabilidades para as instituições formativas e empregadoras; para os professores e demais profissionais da educação; bem como, para a família e a sociedade. Dessa forma os esforços dos professores, por mais árduos que sejam não podem dar conta isoladamente do papel de educar os cidadãos para o século XXI.

Os professores estão sendo cobrados por todos os lados, porém as condições para desenvolver seus trabalhos não estão compatíveis com o grau das exigências e com as responsabilidades que têm. Essas cobranças vêm da gestão das escolas, do sistema de ensino, dos pais e da sociedade. Cada sujeito deve cumprir sua parte nesse processo complexo e indispensável para o desenvolvimento humano.

É preciso que a gestão esteja atenta os desafios dos professores e busque solucionar ou amenizar os mesmos no âmbito da escola, para que estes tenham condições materiais e psicológicas para realizarem seus trabalhos. Os pais devem acompanhar a vida escolar dos filhos auxiliando-os em suas dificuldades e sendo parceiros da escola. Muitas vezes os pais mandam seus filhos para a escola sem o mínimo de atitude educativa que deveriam ter aprendido em casa. A mídia tem mostrado nos últimos tempos como alguns alunos desrespeitam seus professores, que ao se sentirem impotentes e sem apoio ficam doentes. Esta é uma questão que ainda não tem a atenção devida, tendo em vista que prejudica a saúde e o desempenho dos professores e a qualidade da educação.

Como diz um proverbio africano "é preciso toda uma aldeia para educar uma criança". É preciso defender o direito do aluno de aprender e igualmente o direito do professor de ser respeitados no seu espaço de ensinar. As estatísticas mostram que está diminuindo o número de pessoas que querem ser professores. Assim, essa é uma questão social que requer um tratamento sério e urgente, considerando que o professor ocupa um papel estratégico na formação dos humanos.

O Artigo $3^{\circ}$ da Declaração Universal dos Direitos Humanos apregoa que toda pessoa tem direito a segurança pessoal. O Artigo 23 da mesma Declaração §1. Esclarece que toda pessoa tem direito ao trabalho, a condições justas e favoráveis para realizá-lo. Essa 
Declaração tem 60 anos e se o Brasil e o mundo tivessem seguido seus propósitos com esmero, não precisaria ter criado tantas Leis para reforçar o que está no documento em questão.

Tanto alunos, quanto professores devem usufruir de seus direitos e cumprir igualmente seus deveres. Vale destacar que se por um lado os alunos ainda não estão recebendo a educação com a qualidade merecida, por outro os professores estão numa posição de desvalorização profissional e pessoal, que fere a dignidade humana e que por extensão tem implicações nefastas para o desenvolvimento integral de ambos.

Os governantes e a sociedade precisam reconhecer não somente nas páginas dos diversos documentos que oferecem as bases legais da educação e dos direitos humanos, mas, sobretudo, na prática dos sujeitos professor/aluno, do contrário, as referidas legislações continuarão a se evidenciarem entre as mais belas do planeta, sem gerar as transformações que trazem em seus bojos.

\section{Considerações Finais}

Atualmente os avanços da ciência e da tecnologia têm possibilitados vários estudos no campo da neurociência, os quais indicam que cada ser tem um perfil de aprendizagem. Assim, os professores precisam estar atentos para essa questão visando possibilitar as condições adequadas para que os alunos aprendam, visto que na contemporaneidade, a educação é direito de todos.

O direito de aprender da criança e do adolescente está garantido pela legislação brasileira de forma exemplar. Os professores estão sendo cobrados por todos os lados, porém as condições para desenvolver seus trabalhos não estão compatíveis com o grau das exigências e com as responsabilidades que têm.

É preciso que a gestão esteja atenta aos desafios dos professores e busque solucionar ou amenizar os mesmos, para que estes tenham condições materiais e psicológicas para realizarem seus trabalhos. Os pais devem acompanhar a vida escolar dos filhos auxiliando-os em suas dificuldades e sendo parceiros da escola. 
A mídia tem mostrado nos últimos tempos como alguns alunos desrespeitam seus professores, que ao se sentirem impotentes e sem apoio ficam doentes. Esta é uma questão que ainda não tem a atenção devida, que tem prejudicado a saúde e o desempenho dos professores e a qualidade da educação.

É preciso defender o direito do aluno de aprender e igualmente o direito do professor de ser respeitados no seu espaço de ensinar. Os governantes e a sociedade precisam reconhecer não somente nas páginas dos diversos documentos que oferecem as bases legais da educação e dos direitos humanos, mas, sobretudo, na prática dos sujeitos professor/aluno, do contrário, as referidas legislações continuarão a se evidenciarem entre as mais belas do planeta, sem gerar as transformações que trazem em seus bojos.

\section{Referências}

BRASIL. Constituição da República Federativa do Brasil. Brasília: Câmara dos Deputados, 1988.

BRASIL (1996). Lei $n^{\circ}$ 9394, de 20/12/96. Lei de Diretrizes e Bases da Educação Nacional. Diário Oficial da União, ano CXXXIV, N 248, 23/12/96, pp.27.833-27.841. (Brasil). No 9394/96.

BRASIL. Lei n. 8.069, de 13 de julho de 1990. Estatuto da Criança e do Adolescente. Brasília. DOU 16/07/1999.

GHIRALDELLI Jr.História da Educação. $2^{\mathrm{a}}$ Ed. (Coleção Magistério. $2^{\circ}$ Grau. Série Formação do Professor). São Paulo: Cortez, 2000.

MATO GROSSO. Secretaria de Educação de Mato Grosso. Educação Básica. Orientações Curriculares de Mato Grosso - Concepções para a Educação Básica. Cuiabá: DEFANTI, 2012.

MATO GROSSO. Secretaria de Estado de Educação de Mato Grosso. Escola Ciclada de Mato Grosso: novos tempos e espaços para ensinar - aprender a sentir, ser e fazer, Cuiabá, SEDUC 2000.

Como citar este artigo (Formato ABNT):

MARQUES, Marilaine de C.P.; VENTURIN, Valeriana de F.; SANTOS, Simone J. A. da; ZINELLI, Marlize R. O Direio de Aprender dos Estudantes e o Direito dos Professores de Ensinar com Dignidade. Id on Line Revista Multidisciplinar e de Psicologia, 2017, vol.11, n.37, p. 380-391. ISSN: 1981-1179.

Recebido: 30.08 .2017

Aceito: 01.09 .2017 